\title{
Response to Capsule Commentary
}

\author{
Sean M. Phelan, PhD MPH' and Michelle van Ryn, PhD MPH'CHANGE Study Team \\ 'Division of Health Care Policy and Research, Mayo Clinic, Rochester, MN, USA; ${ }^{2}$ School of Nursing, Oregon Health \& Science University, Portland, \\ OR, USA.
}

J Gen Intern Med 33(4):403

DOI: $10.1007 / \mathrm{s} 11606-018-4313-1$

(c) Society of General Internal Medicine 2018

\section{Dear Dr. Jackson,}

Thank you for the opportunity to clarify the reasoning behind our decision to exclude LGBT people and Uniformed Services University of the Health Sciences (USUHS) students in our recent paper. ${ }^{1,2}$ USUHS was excluded from the overall CHANGE Study because they describe themselves as a nontraditional school with a year-round curriculum and focus on military service. The focus of the CHANGE Study was medical school factors and their influence on student attitudes. If USUHS was an outlier in curriculum or student experiences, they might require subgroup analysis that would risk identifying the school. Since it was important to us not to identify any specific school included in the study, we decided to exclude it. We want to stress that longitudinal data was not collected from this school, and thus the decision to exclude had nothing to do with assumptions related specifically to the topic of this paper.

We omitted sexual minority participants from the results because we believe that their attitudes and experiences regarding sexual prejudice warrant individualized attention. Including them in a sample of mostly heterosexual students would cloud the issues at hand. Examining students' attitudes about a stigmatized group to which they belong warrants a different kind of conceptual focus (e.g., internalized stigma might be relevant, intergroup contact might be less relevant), and a manuscript mostly about intergroup prejudice would have had to gloss over the topic.

We also wish to address your suggestion that "What we need in the field of discrimination, whether on the basis of gender, color or sexual orientation, is to move away from descriptive studies that document existence of the problem, and that provide associations which may or may not be causal, and to move toward testing interventions to see whether they can reduce these biases." We wholeheartedly agree that developing and testing more interventions is important and necessary. However, we contend that research documenting and providing new insights into the structural, social, and psychological influences in specific types of biases is essential for developing effective interventions. Although social biases of different types (e.g., racial, gender, sexual orientation) may share some properties and involve common mechanisms (e.g., stereotyping), these biases also differ fundamentally in their nature and dynamics. Thus, past work on race or gender bias may be limited in its contribution to understanding causes and consequences of sexual orientation bias.

Sincerely,

Sean M. Phelan

Michelle van Ryn

CHANGE Study Team

Corresponding Author: Sean M. Phelan, PhD MPH; Division of Health Care Policy and Research Mayo Clinic, Rochester, MN, USA (e-mail: Phelan.sean@mayo.edu).

\section{REFERENCES}

1. Phelan SM, Burke SE, Hardeman RR, et al. Medical School Factors Associated with Changes in Implicit and Explicit Bias Against Gay and Lesbian People among 3492 Graduating Medical Students. J Gen Intern Med. 2017;32(11):1193-1201.

2. Jackson JL. Capsule Commentary on Phelan et al., Medical School Factors Associated with Changes in Implicit and Explicit Bias Against Gay and Lesbian People among 3492 Graduating Medical Students. J Gen Intern Med. 2017;32(11):1248. 